\title{
Teaching Review Approach for Pediatric Trauma
}

\author{
Adel Hamed Elbaih MD ${ }^{1,2^{*}}$, Sohaib Mohammed Gaashan ${ }^{2}$ \\ ${ }^{1}$ Emergency Medicine Department, Faculty of Medicine, Suez Canal University, Ismailia, Egypt \\ ${ }^{2}$ Emergency Medicine, Clinical Medicine Science Department, Sulaiman Al Rajhi University, Al Bukayriah, \\ Saudi Arabia
}

*Corresponding Author: Dr. Adel Hamed Elbaih, MD, Associate Professor, Emergency Medicine Department, Faculty of Medicine, Suez Canal University and Clinical Medicine Science Department, Sulaiman Al Rajhi University, Al Bukayriah, Saudi Arabia.

\begin{abstract}
Background: Traumatic brain injuries are the leading cause of death or severe disability in children older than 1 year, and the incidence is continuing to increase accounts for approximately $50 \%$ of accidental deaths. It is not recommended that all children presenting with head trauma obtain a head computed tomographic scan. Rather, this decision should be based on the mechanism of injury and the signs and symptoms of the patient. Therefore, we aim to look into Pediatric Trauma for both medical students and new physicians face in the recognition, diagnosis and management of these problems.
\end{abstract}

Targeted Population: Pediatrics Trauma is requiring urgent management in the ER and operative room, So Emergency Physicians need teaching approach protocol.

Aim of the study: Appropriate approach of Pediatric Trauma and management by training protocol to Emergency Physicians. Based to Practice Gap prevent pediatric death and adverse long-term complications.

Methods: Collection of all possible available data about pediatric trauma at the emergency department. By many research questions to achieve these aims so a midline literature search was performed with the keywords "critical care", "emergency medicine", "Pediatric Trauma principals in emergencies", "Pediatric Trauma and management". Literature search included an overview of recent definition, causes and recent therapeutic interventions strategies.

Results: All studies introduced that the initial diagnosis of different emergencies situations of Pediatric Trauma and their interventions are serious conditions that face patients at the emergency departments especially traumatic brain injuries.

Conclusion: Pediatric Trauma guidelines will help resolve much of the guesswork that many primary care providers have to consider when evaluating children who have sustained some form of head trauma. And clinicians should be aware of the most recent guidelines for the management of Pediatric Trauma, including the need for imaging, and should be able to differentiate mild from moderate and severe traumatic brain injury

Keywords: Pediatric Trauma, Management, Emergency physicians, skill approach.

\section{INCIDENCES OF THE PROBLEM}

Traumatic brain injury (TBI) in children over 1year-old is the leading cause of death or serious impairment. The CDC identified the public health risk of TBIs in a study to Congress published by the Centers for Disease Control and Prevention (CDC) in 2018. Researchers reported that TBI specifically included 640,000 emergency room visits and 18,000 hospital stays [1].

TBI etiology varies according to age groups.
The most common cause of TBI is being in the 0 -- to 4-year-old age range. On the other hand, the distribution of injuries caused by falls, assault, and motor vehicle events is almost equal within the 15- to 24-year-old age group. Epidemiologic studies have shown that TBI levels seen in the emergency department have risen since 2001 in all age groups, with children 0 to 24 years of age having the highest TBI levels of all age groups. Kids 0 to 4 years of age have almost double the TBI prevalence relative to the next highest age group (15-24 years of 
age), making pediatric traumatic brain injury a highly popular subject for the modern-day pediatrician. In addition, 61 per cent of children with moderate to severe TBI had a disability [2].

Estimates suggest that at least 145,000 children between the ages of 0 and 19 are actually living with long-term symptoms due to TBI(probably under-reporting of moderate TBI [mTBI]), with symptoms lasting well past their initial visit to the hospital in the months and years that followed. Even children with no visible neurological deficiencies arising from their TBI can exhibit weakness in academic performance, attention and focus, memory, and executive function, some of which only become evident months or years after the initial injury [3].

The economic effect of TBI is significant, with estimates for TBI-associated hospitalizations ranging from $\$ 77.9$ million per year in direct costs to more than $\$ 1$ billion per year [4].

\subsection{Blunt Traumatic Brain Injury}

Blunt traumatic brain injury (TBI) is a disruption in the normal function of the brain caused by a mechanical impact to the head. TBI ranges from mild to severe and/or fatal. TBI can be conceptualized as a primary event occurring at the moment of impact, followed by secondary damage due to edema and elevated intracranial pressure. Early identification and management of traumatic brain injury are crucial in halting the progression of the primary insult and preventing or reducing secondary brain injury. TBI is typically classified as mild, moderate or severe, based on the Glasgow coma scale (GCS) [4].

Patients with a GCS of 14 to 15 are considered to have mild TBI, while patients with a GCS of 9 to 13 have moderate TBI, and those with a GCS of 3 to 8 have severe TBI. Initial symptoms of moderate-severe TBI in children are similar to adults, but the ultimate functional impact in children who survive TBI becomes more apparent as the child ages and faces increased challenges in processing information, reasoning, and impaired judgment [5].

\section{DEFINITIONS, INDICATIONS CONTRAINDICATIONS}

AND

A child's head occupies a relatively larger proportion of body surface area than an adult's. Bony sutures fuse by 18 to 24 months. A child's brain has a larger proportion of unmyelinated fibers, making it more susceptible to shear injury [5]

\subsection{Etiology}

The most common causes of TBI in children are falls and sports/recreation-related injuries. Falls (striking the head) are more common in very young children because of their underdeveloped ambulatory skills combined with disproportionately large heads, a shifted center of gravity, and immature neck muscles. Less common, but more severe etiologies of TBI include non-accidental trauma and motor vehicle-related injuries including pedestrians struck by a vehicle (6).

\subsection{Primary Brain Lesions}

1. Appear as an immediate consequence of a traumatic agent [6].

2. Linear forces generate focal lesions such as intracranial hemorrhages and contusions (brain parenchyma strikes skeletal prominences resulting in lesions at the site of the stroke but also counter-kick injuries on the opposite site) [7].

3. The clinical symptomatology of traumatic brain injuries is closely related to the location and severity of the trauma [7].

4. Acceleration-deceleration lesions can also generate angular forces, resulting in axonal shear (primary axotomy). These lesions can be suspected in children whose neurological deficit is not correlated with the apparently minor lesions seen on computed tomography (CT) Scan [6].

\subsection{Secondary Brain Damage}

Appear immediately or late, in two forms:

First form includes metabolic alterations such as hypoxemia, hypotension, increased intracranial pressure (ICP) and Intracranial hypertension, (ICH), hypercapnia or, hyper / hypoglycemia, electrolyte imbalances, expanded hematoma, coagulopathy, epileptic seizures, and hyperthermia. this form can be avoided by treatment [7].

The second form includes the sequence of cellular events that lead to neuro-degeneration and ultimately to neuronal death. The involved mechanisms are: cerebro-vascular barrier alteration, diffuse axonal lesions, necrosis, apoptosis, and inflammation. Although serious research is being undertaken in this area, there is no current treatment for this form of secondary injury [8].

Head injury is common in the pediatric 
population and accounts for approximately $50 \%$ of accidental deaths, with motor vehicle accidents being the leading cause [6].

a. Scalp lacerations may cause extensive blood loss in children, and pressure should be applied to control bleeding [7].

b. Most skull fractures in children are linear and may have no associated symptoms except local tenderness. Depressed skull fractures usually result from direct blunt trauma and may be open. Basilar skull fractures include fractures in the basal portion of the frontal, temporal, and occipital bones, and ethmoid and sphenoid fractures. Findings are the same as those seen in the adult [8].

c. Epidural and subdural hematomas are relatively uncommon and occur more frequently in older children. Diagnosis and management principles are the same in child as in adults. Approximately $75 \%$ of these children continue to have seizures.

With all the related morbidity and mortality, it's important to educate pediatricians to identify and treat TBIs and their sequelae. mTBI typically manifesting as a concussion, but moderate and severe TBIs are more often encountered in the emergency department and hospital setting [9].

- Based on a many study, it is not recommended that all children presenting with head trauma obtain a head computed tomographic scan. Instead this assessment would be based on the patient's injury process and signs and symptoms.

- Concussion symptom checklists such as the Child Sport Concussion Assessment System, the Post-Concussion Symptom Scale or the Graded Symptom Checklist, based on numerous observational studies and expert opinion, can be used to aid in the diagnosis of concussion and to monitor symptom resolution in assessing graded return to playas in table (3) Clinical Phenotypes of Concussion [10].

- Children with moderate to serious traumatic brain injury are at high risk for increased intracranial pressure; this is especially true of children with altered perception.

- Traumatic head trauma is the number one cause of child head injury. The morbidity and mortality of abusive head trauma are considerable, with up to $20 \%$ of the infants succumbing to their injuries and two-thirds of the survivors having significant cognitive and/or physical impairments [11].

Table3. Clinical Phenotypes of Concussion

\begin{tabular}{|c|c|c|c|}
\hline & $\begin{array}{l}\text { CLINICAL } \\
\text { PHENOTYPE }\end{array}$ & SYMPTOMS & SPECIFIC TESTING \\
\hline C & Cognitive function & $\begin{array}{l}\text { Memory impairment, decreased attention and } \\
\text { concentration, slowed processing speed }\end{array}$ & $\begin{array}{l}\text { Neuropsychological testing (in person or computer- } \\
\text { based, such as ImPACT testing) }\end{array}$ \\
\hline 0 & $\begin{array}{l}\text { Oculomotor } \\
\text { dysfunction }\end{array}$ & $\begin{array}{l}\text { Convergence insufficiency, blurred vision, abnormal } \\
\text { saccades and/or smooth pursuit, photophobia }\end{array}$ & $\begin{array}{l}\text { Visual acuity testing } \\
\text { King-Devick test (assess saccadic eye movements) }\end{array}$ \\
\hline A & Affective disturbances & $\begin{array}{l}\text { Fatigue, sadness, irritability, sleep disturbance, poor } \\
\text { concentration, emotionality }\end{array}$ & Depression screen \\
\hline$C$ & Cervical spine disorders & Neck pain, headaches, dizziness, balance difficulty & $\begin{array}{l}\text { Neck range of motion } \\
\text { Palpation of bones and muscles of the neck }\end{array}$ \\
\hline H & Headaches & Migrainous, tension-type, or cervicogenic headaches & - \\
\hline C & $\begin{array}{l}\text { Cardiovascular } \\
\text { anomaly }\end{array}$ & $\begin{array}{l}\text { Exercise intolerance, heart rate variability or elevation, } \\
\text { postural orthostatic tachycardia syndrome, autonomic } \\
\text { dysfunction }\end{array}$ & $\begin{array}{l}\text { Orthostatic vital signs } \\
\text { Exercise stress test } \\
\text { Tilt table testing }\end{array}$ \\
\hline V & Vestibular dysfunction & Dizziness, vertigo, balance difficulties & $\begin{array}{l}\text { Romberg test } \\
\text { Tandem gait } \\
\text { Vestibulo-ocular reflex } \\
\text { Balance Error Scoring System (see the Child Sport } \\
\text { Concussion Assessment Tool) }\end{array}$ \\
\hline
\end{tabular}




\section{Methodology}

This section includes Collection of all possible available data about pediatric trauma at the emergency department. By many research questions to achieve these aims so a midline literature search was performed with the keywords "critical care", "emergency medicine", "pediatric trauma principal's emergencies", " traumatic brain injuries with cardiac arrest". Literature search included an overview of recent definition, causes and recent therapeutic interventions strategies.

So the aims and outcome of the study: initial assessment and evaluate of pediatric trauma for both medical students and new physicians face in the recognition, diagnosis and management of trauma patients; with cardiac arrest to recognize potentially life-threatening conditions and to convey life-saving treatment so the key note here is that initial diagnosis in suspected cases with rapid emergency interventions.

\subsection{Description of a Problem, A Lack of Knowledge on a Certain Topic Or A Segment On WHY this is a Problem}

\subsubsection{Practice Gap}

There is also some uncertainty about the treatment of concussions. With concussions a disproportionate amount of head-calculated tomographic scans are collected resulting in needless exposure to ionizing radiation. Clinicians should be aware of the current recommendations for concussion treatment, including the need for screening, and should be able to differentiate mild from moderate and severe traumatic brain injury [12].

\subsubsection{WHY this Study is Necessary}

Head trauma is a major cause of child morbidity and mortality. More than 750,000 children and teenagers with head injuries present at U.S. EDs annually, double that of a decade earlier. The largest prevalence is in the age group of 0-- to 4 years. Annual rates of United States childhood sports-related concussion vary from 1.1 million to 1.9 million. While most of the concussions are not seen in clinical facilities, an estimated 378,000 cases were considered outpatient visits, 150,000 were referred to the ED, and 5,000 were admitted to hospitals in the United States alone annually. Historically, concussion, minor injury to the head and mild traumatic brain injury have different definitions in medical literature [13].

Glasgow Coma Scale (GCS) score of 14 or 15 is usually specified for minor head injury at the time of presentation to the ED.A consensus definition of concussion was derived at a major conference of commotion specialists in Berlin in 2016:Biomechanical movements caused traumatic brain injury [14].

Concussion may be caused by a direct impact with an impulsive force delivered to the head, face, back, or elsewhere on the body.

Usually, it results in the sudden onset of shortlived neurological function dysfunction, which recovers spontaneously. However, certain cases, however, signs and symptoms develop over a period of minutes to hours [15].

\subsection{Segment that Underlines the Research Question that should be answered (Based on the Problem Describe Earlier)}

\subsubsection{Workup: To Image or Not to Image}

ED management of patients with minor head injury focuses on diagnostic workup/imaging, pain management, ED observation, patient disposition, and parent/provider education. After the initial assessment, the EP must synthesize the history and physical findings and decide if the potential risk of TBI is sufficient to warrant CT imaging. History and physical exam, while crucial, are non-specific. Validated tools to help the physician assess population-based risk are imperative to the appropriate management of minor head injury. The physician should then incorporate the pros and cons of radiation vs. the risk of a significant TBI in a discussion with the parents regarding the decision to image [13]

the number of children presenting TBIs to emergency departments, it is more critical than ever that clinicians assess children appropriately to decide if head CT is required and to prevent excessive and dangerous exposure to radiation. Fortunately, the Pediatric Emergency Care Applied Research Network (PECARN) Criteria for CT Brain has developed a well-validated set of clinical criteria to help in this decision making process. Past attempts to incorporate these standards in a regional emergency department resulted in lower head CT scan 
levels in children with head injuries, suggesting that this is an ideal opportunity for more quality improvement programs as in Figure (2) Pediatric Emergency Care Applied Research Network (PECARN) Criteria for CT Brain:Project: Reduction of head CT scan levels in children with headache [16].
Setting: Department of Emergency services.

Resource for diagnosis: PECARN rule for diagnosis of clinically significant TBIs.

Outcome Measure: Pediatric head CTs rate in TBI-presenting babies as in Table (4) Predictors Variables and Outcome Measures for Pediatric Trauma.

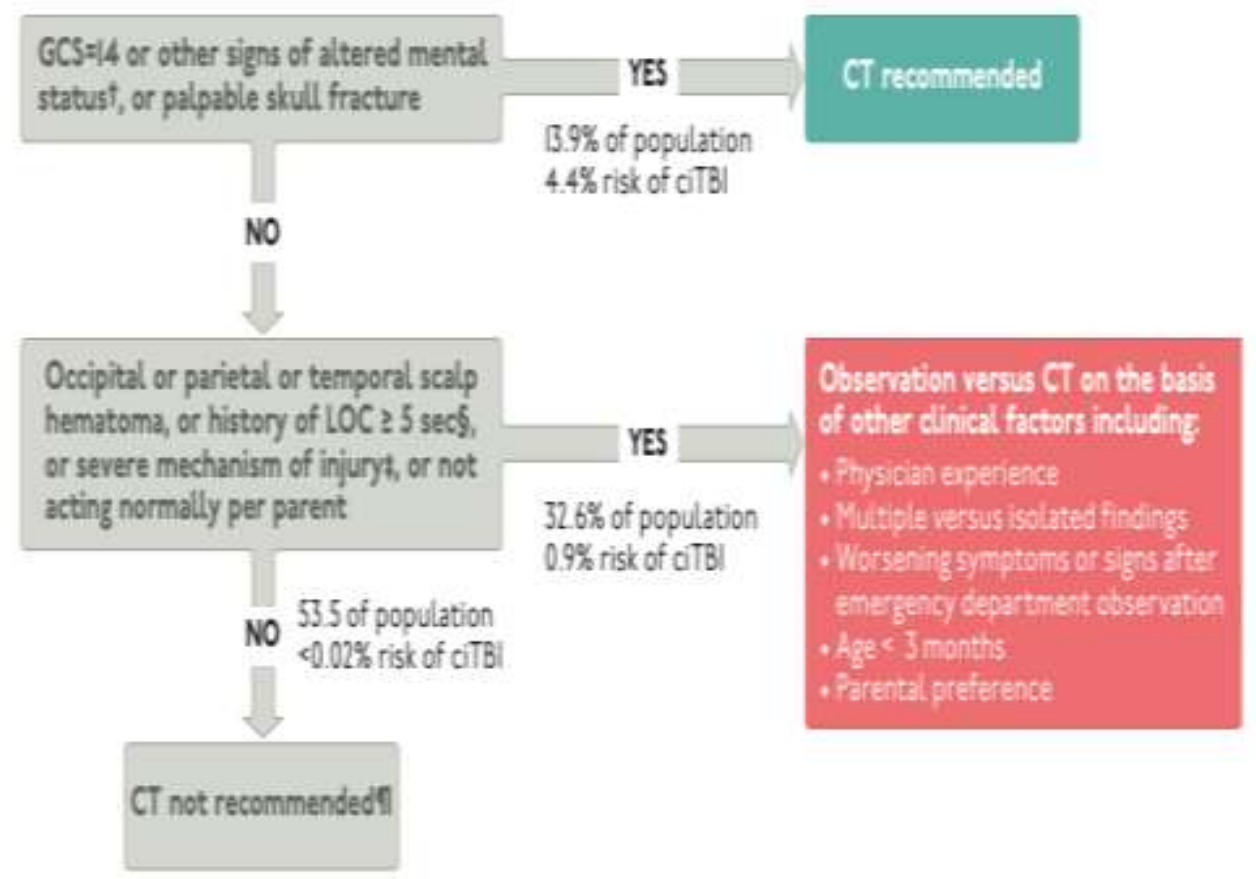

A

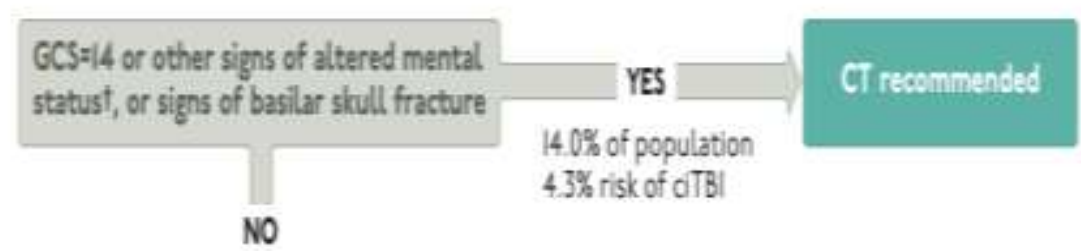

Kistory of $L O C$, or history of vomiting, or severe mechanism of injuryt, or severe headache

58.3 of population $0.05 \%$ risk of oTB

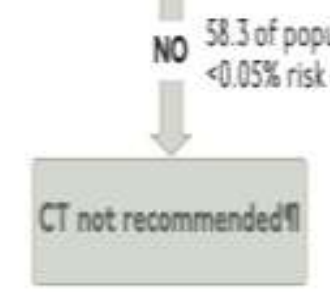

Obsenation versus CT on the basis of other clinical factors including? - Physican enperience - Milipleversusisalated findings. - Worseningsymptoms or signs alter energency department coservation - Parentelpreficence

Figure2. Pediatric Emergency Care Applied Research Network (PECARN) Criteria for CT Brain 
Table4. Predictor Variables and Outcome Measures for Pediatric Trauma

\begin{tabular}{|c|c|c|c|c|c|}
\hline & PECAPN $<2 y$ & PLCARN $\geq 2 y$ & CATCH & CHALCE & Nexus II \\
\hline $\begin{array}{l}\text { Primary } \\
\text { outtome }\end{array}$ & \multicolumn{2}{|c|}{$\begin{array}{l}\text { Cinically important traumatic brain injung, defined as death } \\
\text { from traumatic brain injury, neurosurgical intervention for } \\
\text { traumatic brain injury (intracranial pressure monitoring. } \\
\text { elevation of depressed skull fracture, ventriculostony, } \\
\text { hematoma evacuation, lobectomy, tissue debridenent. } \\
\text { dura repair, other), intubation of }>24 \mathrm{~h} \text { for traumatic } \\
\text { brain injury or hospital admission of } 2 \text { nights or mone for } \\
\text { traumatic brain injury in association with traumatic brain } \\
\text { injury on of }\end{array}$} & $\begin{array}{l}\text { Need for neuralogic } \\
\text { intervention; defined as } \\
\text { either death wittin } 7 d \\
\text { secondary to the head injury } \\
\text { of need for any of the } \\
\text { following peocedures within } \\
7 \text { days craniotomy, elevation } \\
\text { of skall fracture, monitoring } \\
\text { of intracranial pressure. } \\
\text { insertion of endotracieal } \\
\text { tube for the management of } \\
\text { head injury }\end{array}$ & $\begin{array}{l}\text { Cinically significant intracranial } \\
\text { injury; defined as death as a result } \\
\text { of hesd injury, requirement for } \\
\text { neurosurgical intervention, of } \\
\text { marked abnormality on (c } \\
\text { (defined as any new, acute. } \\
\text { traumatic intracanial pathology as } \\
\text { reported by consultant radiologist. } \\
\text { induding intracanial hematomas } \\
\text { of any size, cerebral conturion, } \\
\text { diffuse cerebral edema, and } \\
\text { depressed skull fractures) }\end{array}$ & 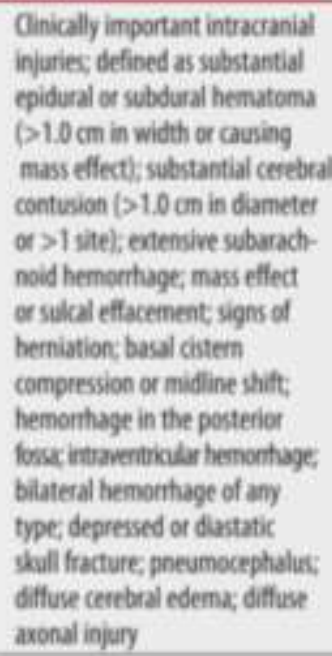 \\
\hline \multicolumn{6}{|c|}{ Predictor variable" } \\
\hline Mechanism & $\begin{array}{l}\text { Severe mechaniam of injury } \\
\text { OMV with patient ejection, } \\
\text { death of another passenger. } \\
\text { or rollover, pedestrian/ } \\
\text { bicgdat without helmet } \\
\text { struck by motorized vehide; } \\
\text { falls }>0.9 \text { mc head strudk by } \\
\text { high-impact object) }\end{array}$ & $\begin{array}{l}\text { Severe mechanism of injury } \\
\text { (MVC with potient ejection, } \\
\text { death of another passenget, } \\
\text { or rollover pedestrian: } \\
\text { bicydist without helmet } \\
\text { struck by motoriued vehide: } \\
\text { falls }>15 \text { mt head struck by } \\
\text { high-impact object) }\end{array}$ & $\begin{array}{l}\text { Dangerous mechanism of } \\
\text { injury (e.g. MVC, fall from } \\
\text { elevation } \geq 3 \mathrm{ft}(\geq 91 \mathrm{~cm}) \\
\text { o } 5 \text { stains fall frem bicgde } \\
\text { with no helmet) }\end{array}$ & $\begin{array}{l}\text { High-speed RTA as pedestrian. } \\
\text { godist, occupant (defined as } \\
\text { acdident with speed }>40 \text { mph or } \\
64 \mathrm{~km} / \mathrm{h} \text { ) } \\
\text { Fall }>3 \mathrm{~m} \text { in height } \\
\text { High-speed injury from projectile } \\
\text { or abject }\end{array}$ & $\begin{array}{l}\text { Persistent vamitiog } \\
\text { Altered level of alertness, } \\
\text { abnormul behavior } \\
\text { Coagulopathy }\end{array}$ \\
\hline Histeny & $\begin{array}{l}10 C z 5 s \\
\text { Not acting normally per } \\
\text { purent }\end{array}$ & $\begin{array}{l}\text { Any or suspected } L C \\
\text { History of vomiting } \\
\text { Sevese headache }\end{array}$ & $\begin{array}{l}\text { History of wonening } \\
\text { headache? }\end{array}$ & 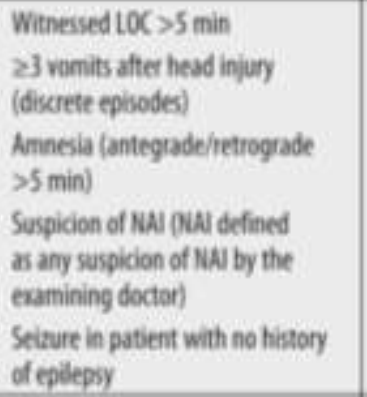 & \\
\hline Examination & $\begin{array}{l}\text { GCS C15 } \\
\text { Other signs of altered } \\
\text { mental status (agitation, } \\
\text { somnolence, repetitive } \\
\text { questioning, slow reponse } \\
\text { to vertal communication) } \\
\text { Palpable or undear shall } \\
\text { fracture } \\
\text { Occipital, parietal, or } \\
\text { temporal scalp hematoma }\end{array}$ & $\begin{array}{l}\text { CSS }<15 \\
\text { Other signs of altered } \\
\text { mental status (agitation. } \\
\text { somnolence, repetitive } \\
\text { questiening, slow response } \\
\text { to vertal communication) } \\
\text { Clinical signs of basilar shull } \\
\text { fracture }\end{array}$ & 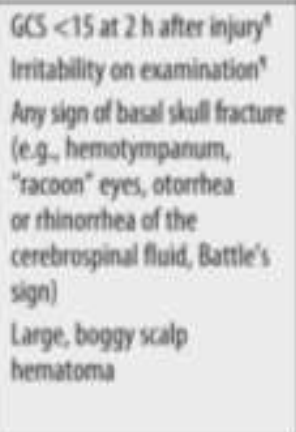 & 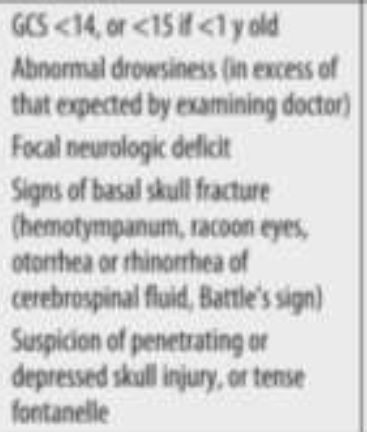 & $\begin{array}{l}\text { Neurologic defict } \\
\text { Abnamal behavior } \\
\text { Evidence of significant shull } \\
\text { fracture } \\
\text { Presence of scalp hematoma }\end{array}$ \\
\hline
\end{tabular}

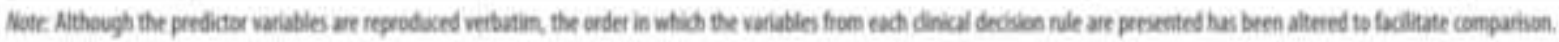

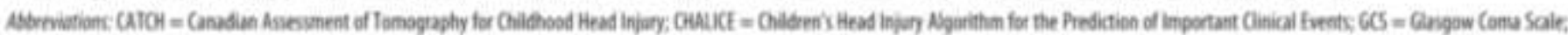

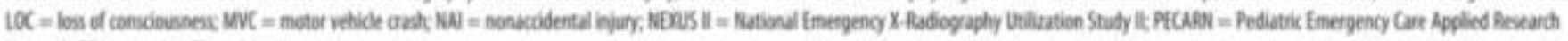
Netwode nta $=$ rad traffic acodeot.

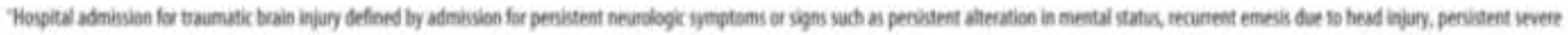
headache, or angoing seizare management.

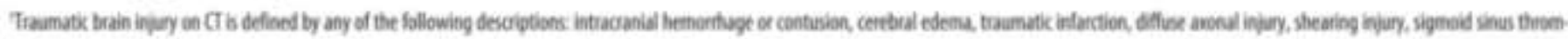

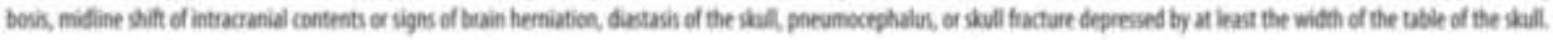

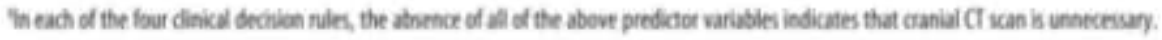

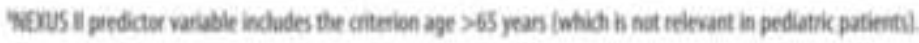

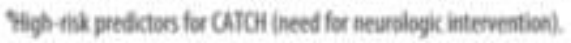


In the secondary survey, entailing a detailed physical examination and history is performed.

* Evidence of trauma is determined by palpating bony prominences and the maxillae and by inspecting the nose and ears for drainage of cerebrospinal fluid (CSF).

* The existence of dehydration is determined by inspecting the mucosae for evidence of decreased tearing or moisture or sunken eyes.

* The eyes should be inspected for pupillary size and extra ocular movements. A funduscopic examination should be performed if possible to assess for central nervous system (CNS) or toxic involvement.

* The oral cavity should be inspected for odor or discoloration that may imply a toxicologic basis for the condition.

In infants younger than a year of age, the anterior fontanel should be assessed for bulging (intracranial hypertension, bleeding) or depression (dehydration).

Head trauma is a major cause of child morbidity and mortality. More than 750,000 children and teenagers with head injuries present at U.S. EDs annually, double that of a decade earlier. The largest prevalence is in the age group of 0 -- to 4 years [17].

Annual rates of United States childhood sportsrelated concussion vary from 1.1 million to 1.9 million. While most of the concussions are not seen in clinical facilities, an estimated 378,000 cases were considered outpatient visits, 150,000 were referred to the $\mathrm{ED}$, and 5,000 were admitted to hospitals in the United States alone annually. Historically, concussion, minor injury to the head and mild traumatic brain injury have different definitions in medical literature [15].

As in table (2) Pediatric Glasgow Coma (GCS) score of 14 or 15 is usually specified for minor head injury at the time of presentation to the ED. A consensus definition of concussion was developed at a major conference of concussion specialists held in Berlin in 2016: traumatic brain injury caused by biomechanical forces. Concussion may be caused by a direct impact with an impulsive force delivered to the head, face, back, or elsewhere on the body. Usually, it results in the sudden onset of short-lived neurological function dysfunction, which recovers spontaneously. However, in some cases, signs and symptoms evolve over a number of minutes to hours [12].

Table2. Pediatric Glasgow Coma Scale

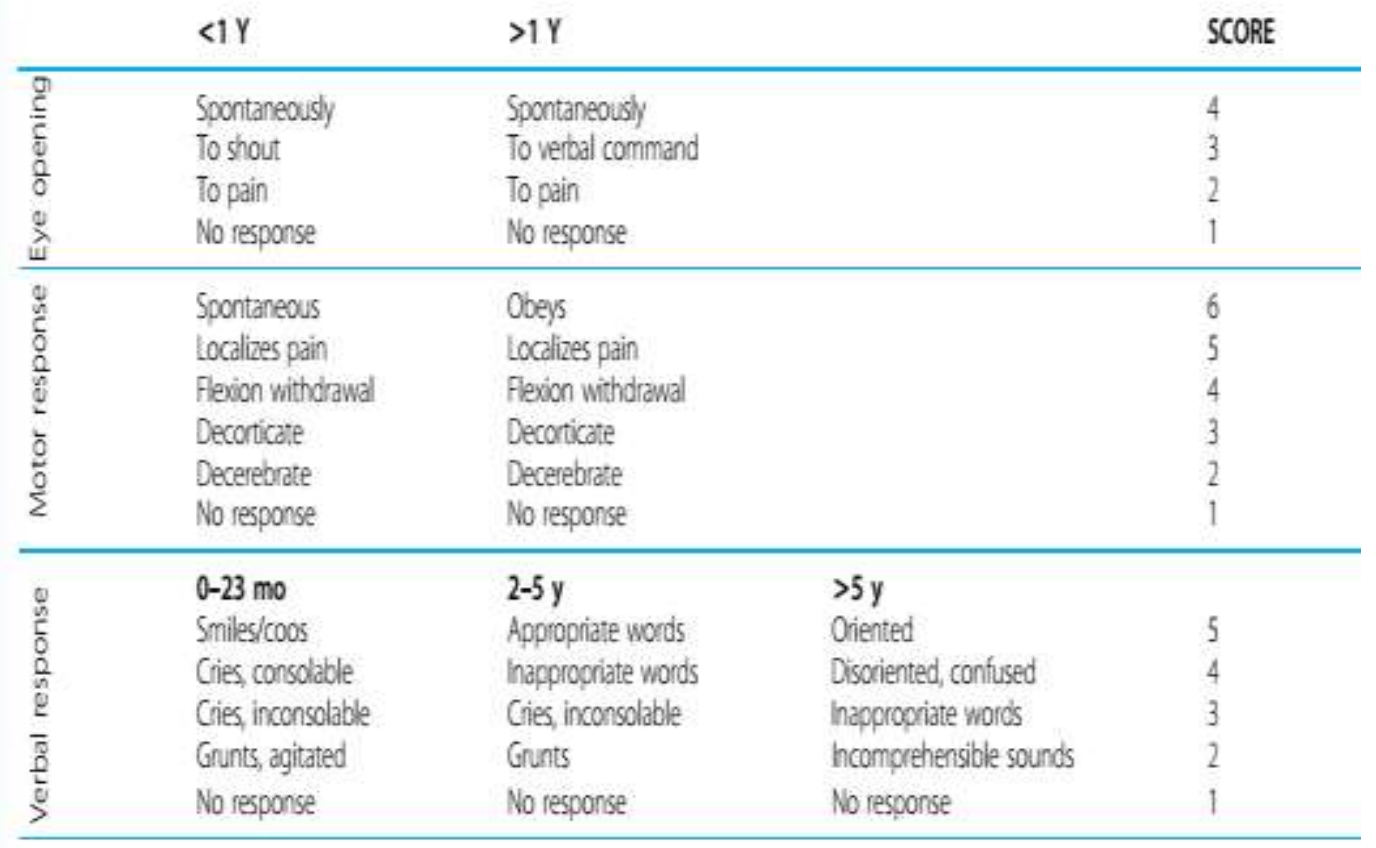

\subsubsection{Disposition}

The disposition of a child with minor head trauma depends on several factors: age of the patient, access to care, and the parents' comfort level. The options include: admission, observation, and discharge home with comprehensive parental instructions [11]. 


\subsubsection{ED Observation}

Patients with a very low suspicion for intracranial injury may be observed for a short period of time after the injury. If the child has clinically improved (more alert, oriented, headache resolution, tolerating oral intake), then observation may be continued at home. In general, for low-risk, asymptomatic patients, a period of caregiver and ED observation of four to six hours post injury is reasonable and supported in consensus guidelines [12].

\subsubsection{Admission}

If a patient has ongoing symptoms during the course of the ED stay, he or she should be imaged. While there may be times when a CT is not performed initially because of parental preference, if the child does not look well, or has high-risk features that the physician is concerned about, then it is reasonable to recommend imaging [13].

There will be a certain percentage of patients with negative CT scans who continue to be symptomatic. They may become irritable, have pain control issues, or continued vomiting. For these patients, it is reasonable to observe them in the hospital to ensure that their symptoms improve. If they do not improve, additional care and work-up may be warranted. Parents should be informed that the likelihood of a delayed intracranial bleed is exceedingly low, especially with a negative CT scan. Children with suspicion for non-accidental trauma also warrant admission for observation and involvement of social services. Furthermore, inpatient observation is also acceptable if parents and caregivers of the child seem unreliable or unable to return to the ED or follow-up [14].

Isolated linear and non-depressed skull fractures do not necessitate a neurosurgical consult. These children are at low risk of clinical deterioration and may be considered for discharge. If an intracranial injury is diagnosed, neurosurgical consultation should be obtained. Though the vast majority of traumatic brain injuries are nonsurgical, the neurosurgeon is ultimately responsible for intervening should that patient deteriorate and require operative repair. Children with depressed skull fractures or intracranial injury by CT are usually admitted. Whether the child is admitted to the intensive care unit or regular inpatient bed depends on the patient's clinical status, the severity of injuries, and neurosurgeon preference [14].
The period of time for inpatient observation after head injury has not been established. The AAP practice guidelines recommend at least 24 hours of observation as this is the timeframe in which the majority of complications will present themselves [15].

\subsubsection{Discharge}

If a child has had a negative head CT and is well-appearing, the likelihood of a significant brain injury and delayed sequelae is extremely low. Physicians can inform parents that the incidence of delayed bleeding is close to zero. These children are safe to discharge home. However, even if a child has undergone a CT scan, parental observation of the child and return precautions for concerning signs of intracranial injury (altered mental status, severe headache, dizziness, lethargy, and persistent vomiting) must be given. Parents should be instructed to follow up with their primary physicians in 24 hours [16].

If a child has not undergone a diagnostic CT scan and is at low risk of serious intracranial pathology, he or she also may be discharged for continued observation at home. For most mild head injuries, the practice of waking the child is not necessary. If a well-appearing child initially presented with persistent symptoms or a more severe mechanism of injury, then caregivers can be instructed to wake the child every four hours of sleep for the next 24 hours. Close follow-up should be arranged within 24 hours. A thorough discussion with parents should detail strict return precautions as outlined above and instructions for when to return to the emergency department for evaluation [17].

\section{CONCLUSION}

TBI is composed of a wide range of clinical presentations so there is a difficult for patients and genior physician's assessment so table (1) clarify Checklist for Skill Approach of Pediatric Trauma and also Figure (1) Guidelines checklist for Pediatric Trauma.

These injuries pose a significant challenge for the primary care physician as in the case of mild to extreme TBIs, the prognosis ranges from excellent, with complete recovery in a few days to a few weeks with mTBI to devastating, with serious morbidity and mortality.

A comprehensive approach to the child experiencing a TBI will also help with proper clinical management. Guidelines exist for the management of adult head injury (National 
Institute for Health and Care Excellence's Head Injury: Assessment and Early Management These guidelines have been found to be highly reliable and easily adaptable to multiple environments, including low- and middleincome countries. Now, the CDC has released guidelines for diagnosing and treating $\mathrm{mTBI}$ in infants.
The implementation and acceptance of these recommendations will help to overcome much of the guesswork that many primary care professionals continue to do when treating children who have suffered any type of head trauma.

Table1. Checklist for Assessment Skill Approach of Pediatric Trauma

- Introduce yourself

- Refer to the child by name

- Open question to get the chief complaint

- Establish the need for urgent intervention (if yes,

\section{$A B C$ and resuscitation)}

- If not urgent start with history

- What was the mechanism of the trauma (falling,

MVA, assault, ...etc)

- Depending on the mechanism take a detailed description

- (the height of the falling, the texture of the ground landed on, pedestrian or inside a vehicle, seat belt, helmet, ...etc)

- When it happened

- Child's immediate status after the trauma

- Loss of consciousness

- Vomiting

- Lethargy

- Imitability
- Amnesia (when appropriate age)

- Seizures

- Headache (when appropriate age)

- Blurred vision (when appropriate age)

- Ability to walks steadily (when appropriate age)

- Movement of the limbs

- Any pain in the body (when appropriate age)

- Nasal discharge or bleeding

- Ear discharge or bleeding

- Previous traumas

- Review of systems

- Past medical history

- Medications

- Allergies

- Vaccinations

- Developmental history

- Answer the parents/ child concems

- Summarize and give a plan

- Offer a follow up 


\section{CDC PEDIATRIC mTBI GUIDELINE Checklist}

\section{For healthcare providers treating children 18 years of age and younger}

\section{HEALTHCARE PROVIDERS SHOULD:}

\section{ASSESS.}

Conduct a physical examination to Idemtify findings that:

- Suggest more savere TRl [0.g., hemotympanum, pupllary asynmetry|

- May impact mensgemert of mTBI (p.9, concurrent injurles or bsselne deficits, oculomotor dysfunction)

- Suggest other cortributions to symptoms [0.9, dehydration, corvical tenderness, scalp hematomal.

Do not image routinely [including CT \& MRl).

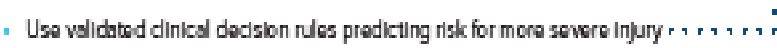
to determhe noed.

Assess symptoms using validsted scsles. Coreider cognithe and balance 1esting ,

Conduct a hisiory to idertify risk factors for poor prognosis using velidsted . . . . . . . . prodetion rules.

\section{COUNSEL.}

Provide intomation about

- Warring signs that injyy may be more seriouk . . . . . . . . . . . . . .

- Typical recovery carse

- How to prevert further hjury.

- Grodual re-intoduction of activity that does not worsen symptoms.

- The need for socisl and emosionsl support.

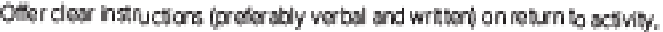
including schod and ports, ostamised to the pasent's symptoms

- After a fow days of rest (2-3 days) begin ight activity \& then gradisly re-introduce regilar acsivities (not indusive of sports) that do not sigrificartly worsen symptams.

Assess school-redstod needs $\&$ moritor progess in collaboration with parents and school professionsts.

- Once backto regiar non-sports activties fincluding schodl pasent can begin remurn to sports uaing a sanderd progression with gradully incressing levela of physical erertion.

- Na rectum to contsct ports setrity unt symptomfree with erertion . . . . . . . . . (induding without the uese of pain medcasort;

\section{REFER.}

Ideraty and tilor trestment plangheforials to sddhess . . . . . . . . . . . . . . .

- Acusely worsering symptoms $\rightarrow$ consider naraimsging.

- Groric has dsche $\rightarrow$ non-cpidid ansiges is (moritar for overuee) muls-dscipinary evalusion.

- Vestibulo-ocular dyafunction $\rightarrow$ vegrbular rehabilitsion

- Worsering sleep problem $\rightarrow$ sleẹ hygiene, slecp specialist.

- Cogrisive impsiment $\rightarrow$ trestmere directed at wology, neuropsychalogical evalusan

- Emotianal dystunction $\rightarrow$ paychotherapeufic evalusison and trestmert.
A combination of risk fectors that maxy indicato need for nouroimaging includes

- Age $<2$ yours old

- Recurrent voriting

- Loss of consclousness

.. . Severe mechanism of Injury

- Severe or worsening hasdsche

- Amnesla

- Nen-frortal scalp hematom

- Glasgew Coma Score <15

- Cirical suspicion for skull fracbure

Eemples of validated seales include, but aren't limited tox

- Post-Concussion Symptom Scale

- Heslth and Behsvor Invertory

- Post-Concussion Symptom Imventory

- Acuia Concussion Evalustion

Factors assoclated with poor prognosis:

- Older sge [older childrenvadolescentsj or Hispank ottriclity

- Lower socia-econerric status

- History of Imtracrarial njury

Premorbid histories of mTlil or hareased pro-Injury symptoms

- Neurologieal or psychiatric disorder

- Lesrring difficultios or lower cognitive ability

Famly and social stressers

Parents should watch for warning signs:

- A hesdache that gets worse \& does not go sway

- SIgnificant nausca or repested womiting

- Incrogsed contusion, restiosscess, or aglitaton

- Slurred speach, drowsiness, or hability to wake up

- Weakness, numbness, or decressed coordinstion

- Loss of coreciousness, convulsions, or solzuros

Stops in a return to play progreesion gonerally include:

Stap 1: Robum to rogular non-sports actwitics

Stap 2: Lught serobic exercise

5tep 3. 5 port-spedfic exerdes

5top 4: Non-contact traning dills

5tap 5: Ful contact practice

5tap 6: Rebum to sport

Rder pationts whoee symptoms do not resolve as expected with standand care after 4.6 wools.

To view the full set of recommendations from the CDC Pedlatric mTBI Guideline, visit www.cdc.gov/HEADSUP.

Figure1. Guidelines checklist for Pediatric Trauma 


\section{REFERENCES}

[1] Elbaih AH. Different Types of Triage. Arşiv Kaynak Tarama Dergisi. Archives Medical Review Journal 2017; 26(4): 441-67. https://doi.org/10.17827/aktd.326944

[2] Fitch, M., Joing, S., Wang, V., Cline, D., Ma, O., Tintinalli, J. and Cydulka, R., 2018. Tintinalli's Emergency Medicine Manual. New York [i 11 pozostałych]: McGraw-Hill Education.

[3] Elbaih AH, Patterns and management of chest injuries patients and its outcome in Emergency Department in Suez Canal University Hospital, Egypt. Medicine Science | International Medical Journal, 2017; 6(2):328-37. https://doi.org/10.5455/medscience.2016.05.8567

[4] Elbaih AH, Arnous KA. Teaching Approach of Emergency Traumatic Chest Injuries: A Review. ARC Journal of Surgery. 2020; 6(2):18. https://doi.org/10.20431/2455-572X.0602001

[5] Huecker, M. and Plantz, S., n.d. Step-Up To Emergency Medicine.

[6] Elbaih AH, Abou EA. Approach for Emergency Traumatic Hemorrhagic Shock. SunText Rev Surg. 2020; 1(1): 105. https://www.suntext.org/journals/suntextreview-of-surgery/fulltext/approach-foremergency-traumatic-hemorrhagic-shock

[7] Elbaih AH, Basyouni FH. Teaching Approach of Primary Survey in Trauma Patients. Int J Intern Emergency Medicine. 2020; 3(3): 1035. http://www.remedypublications.com/openaccess/teaching-approach-of-primary-surveyin-trauma-patients-6295.pdf

[8] Elbaih AH, El-sayed DA, Abou-Zeid AE, Elhadary GK. Patterns of brain injuries associated with maxillofacial fractures and its fate in emergency Egyptian polytrauma patients. Chinese J Traumatology. 2018; 21: 287-292. j.cjtee.2017.12.005

[9] Elbaih AH, Mousa MA. Review Article: Teaching Review on Approach of Esophageal Intubation as Complications in Emergency
Airway Management. American Journal of Surgical Case Reports. Volume 2(3): 2-6 http://dx.doi.org/10.31487/j.AJSCR.2020.03.13

[10] Elbaih AH, Al-Nasser AU. Review on ACLS Approach of Pregnancy in Maternal Collapse. Int J Case Rep Short Rev. 2020;6(8): 038-046. https://dx.doi.org/10.37871/ijcrsr.id81

[11] Gelineau-Morel, R., Zinkus, T. and Le Pichon, J., 2019. Pediatric Head Trauma: A Review and Update. Pediatrics in Review, 40(9), pp.468481.

[12] Elbaih AH, Elsayed ZM, El bahrawey MR, Khalaf MM. Adherence of Emergency Physicians to Pediatric Emergency Care Applied Research Network-Clinical Decision Rule (PECARN-CDR) in Mild Head Trauma in Emergency Patients. Open Scientific Journal of Surgery.1: 43-56. https://doi.org/10.36811/ osjs.2019.110007

[13] Pediatric Minor Head Injury 2.0: Moving from Injury Exclusion to Risk Stratification

[14] Elbaih AH, Ghaleb AN. Teaching Approach for Neonatal Resuscitation in Delivery Room. Narayana Medical Journal. 2020; 9(2): 41-51. https://doi.org/10.5455/nmj/00000192

[15] HENRY, S., 2018. Atls Advanced Trauma Life Support 10Th Edition Student Course Manual, 10E. [Place of publication not identified]: AMERICAN COLLEGE OF SURGEO.

[16] Cdc.gov. 2020. CDC Pediatric Mtbi Guideline | Concussion | Traumatic Brain Injury | CDC Injury Center. [online] Available at: <https://www.cdc.gov/traumaticbraininjury/Ped iatricmTBIGuideline.html> [Accessed 8 June 2020].

[17] Elbaih AH, Mohammed MA, Ali MA, Elshemaly AA, Mostafa MS. Validity of S100B protein as a prognostic tool in isolated severe head injuries in emergency patients. Egypt $\mathbf{J}$ Surg. 2020; 39:795-806. DOI: 10.4103/ejs.ejs_54_20 http://www.ejs.eg.net/ text.asp?2020/39/3/795/293680

Citation: Adel Hamed Elbaih, Sohaib Mohammed Gaashan. "Teaching Review Approach for Pediatric Trauma". ARC Journal of Surgery. 2021; 7(1):13-23. DOI: https://doi.org/10.20431/2455-572X.0701003.

Copyright: (C) 2021 Authors. This is an open-access article distributed under the terms of the Creative Commons Attribution License, which permits unrestricted use, distribution, and reproduction in any medium, provided the original author and source are credited. 